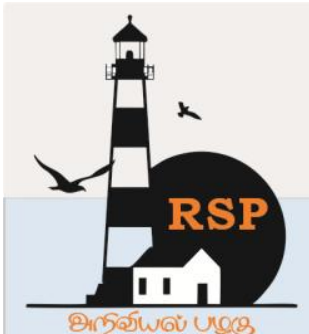

INTERNATIONAL RESEARCH JOURNAL ON ADVANCED SCIENCE HUB

-ISSN : $2582-437$
Open Access

RSP SCIENCE HUB

(The Hub of Research Ideas)

Available online at www.rspsciencehub.com

Special Issue of Second International Conference on Innovation in Engineering Sciences (ICIES2021)

\title{
Experimental investigation on mechanical and FTIR analysis of novel bio materials reinforced epoxy composites
}

\section{S.Meinathan ${ }^{1}$, Kannakumar ${ }^{2}$,P.Gnanvel ${ }^{3}$}

${ }^{l}$ Assistant Professor, Department of Mechanical Engineering, Shree Venkateshwara Hi-Tech Engineering College Othakuthirai, Gobi. Erode (DT) TamilNadu, India.

${ }^{2}$ Assistant Professor, Department of Mechanical Engineering, Shree Venkateshwara Hi-Tech Engineering College Othakuthirai, Gobi. Erode (DT) TamilNadu, India.

${ }^{3}$ PG Scholar, Department of Manufacturing Engineering, Shree Venkateshwara Hi-Tech Engineering College, Othakuthirai, Gobi. Erode (DT) TamilNadu, India.

s.meinathan@gmail.com ${ }^{1}$,kkannakumar@gmail.com ${ }^{2}$, pgnanavelmfg@gmail.com ${ }^{3}$

\begin{abstract}
Today, the world faces unprecedented challenges in social, environmental, and economic dimensions, in which industrial design has shown an important contribution with solutions that provide positive answers regarding such problems. In particular, due to the fast-depleting resources, our dependence on trees has increased which is hampering our environment drastically. Our world confronts a moment of crises, and sustainable development of manufacturing industries provides us with challenges as well as opportunities. In this context, the use of natural fiber composites, produced in developing countries, has presented several social, environmental, and economic advantages to designing "green" substitutes. So Technical properties such as Mechanical and Physical properties are to be conduct and test results will be to calculate and evaluation of the composite property of natural composite fibers done in this project.
\end{abstract}

Keywords:Natural fibre composites, Physical Testing, Mechanical Testing SEM Analysis.

\section{Introduction}

Natural composites exist in both animals and plants. For example, wood and bone are actually composites. Wood contains long cellulose fibers held together by lignin, a much weaker substance. The two weak substances, cellulose, and lignin, together form a much stronger one. The bone-in human body is made from a hard but brittle material called hydroxylapatite (which is mainly calcium phosphate) and a soft and flexible material called collagen, which is a protein. The benefits of composites were known to people from very early days. Fibers are classified by their chemical origin, falling into two groups or families: naturalfibresand manufactured fibers. Manufactured fibers are also referred to as manmade or synthetic fibers.

\subsection{Hybrid Composites}

The characteristics of hybrid composites, which are composites reinforced with more than one natural fiber, are also explored and they have better mechanical strengths than composites. The properties of a hybrid composite mainly depend upon the fiber content, length of individual fibers, the extent of the intermingling of fibers, fiber to matrix bonding, and arrangement-cum- orientation of both the fibers. Maximum hybrid results are obtained when the fibers are highly strained compatible. Hybrid composites containing a mixture of synthetic and natural fibers were also studied and they have better strengths than only natural fiber containing hybrid composites due to the higher strengths of synthetic fiber. 
2. Material and Methodology

Research efforts are made to develop new materials for various engineering applications since any single material does not satisfy the present requirements of lightweight and loadbearing capacity. Hence it is required to develop complex composite materials which include fibers and binders to meet the demands of present-day engineering and general applications.

\subsection{Selection of Materials}

- Flax Fiber

- Snake Grass Fiber
- Tea Leaf Fiber

- Epoxy Resin

\subsection{Research Methodology}

Research efforts are made to develop new materials for various engineering applications since any single material does not satisfy the present requirements of lightweight and loadbearing capacity. Hence it is required to develop complex composite materials which include fibers and binders to meet the demands of the presentday engineering and general applications.

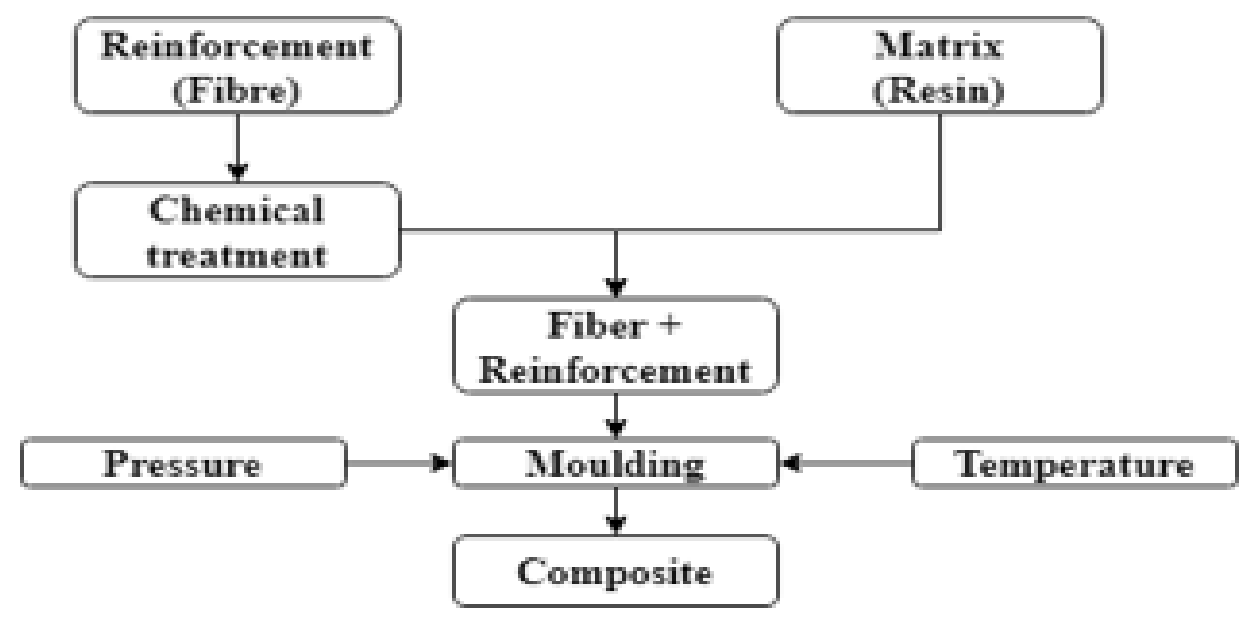

Fig.1 Methodology

\subsection{Chemical Treatment}

Chemical treatment (of hazardous waste) refers to the treatment methods that are used to affect the complete breakdown of hazardous waste into nontoxic gases or, more frequently, to modify the chemical properties of the waste, for example, through reduction of water solubility or neutralization of acidity or alkalinity.

\section{AlkaliTreatment(Mercerization)}

\subsubsection{Reason for Choosing Alkali Treatment}

When compared to other methods,

- Alkali treatment gives more moisture removal

- Alkali treatment gives good mechanical properties

\subsubsection{Compression Molding}

Compression molding is the process of molding in which a preheated polymer is placed into an open, heated mold cavity. Thermoset composites are the most common type of material used in compression molding.

\subsubsection{Experimental Methods Characterization}

Owing to the vast research which has taken place in the past three to four decades, the characterizations of composite materials are important for many applications. In the present research work Flax, Snake grass, and Tealeaf reinforced epoxy matrix-based composite laminates were tested for mechanical and physical properties as per ASTM standards.

To conduct the mechanical and physical properties for the above hybrid composites.

- Density - ASTM D-2734-94

- Tensile Strength - ASTM D638

- Flexural Test - ASTM D790-03

- Interlaminar Shear Strength - ASTM D2344

- Impact Test - ASTM D256

- Water Absorption Tests - ASTM D570-98

- SEM Analysis 


\section{Experimental Datas}

3.1 Density and Void Fraction

Table.1. Densities of different Composite Laminates

\begin{tabular}{|c|c|c|c|}
\hline Laminates & $\begin{array}{c}\text { Theoretical } \\
\text { density (pct) }\end{array}$ & $\begin{array}{c}\text { Experimental } \\
\text { density (pce) }\end{array}$ & $\begin{array}{c}\text { Void } \\
\text { fraction } \\
\text { (Vv) }\end{array}$ \\
\hline & (gm/cc) & (gm/cc) & $\mathbf{( \% )}$ \\
\hline L1 & 1.4972 & 1.4961 & 0.073 \\
\hline L2 & 1.4972 & 1.4953 & 0.127 \\
\hline L3 & 1.2375 & 1.2158 & 1.753 \\
\hline L4 & 1.2375 & 1.2215 & 1.293 \\
\hline L5 & 1.3597 & 1.3457 & 1.029 \\
\hline L6 & 1.3597 & 1.3494 & 0.757 \\
\hline L7 & 1.4059 & 1.4044 & 0.107 \\
\hline L8 & 1.4059 & 1.4046 & 0.092 \\
\hline
\end{tabular}

\subsection{Tensile Strength}

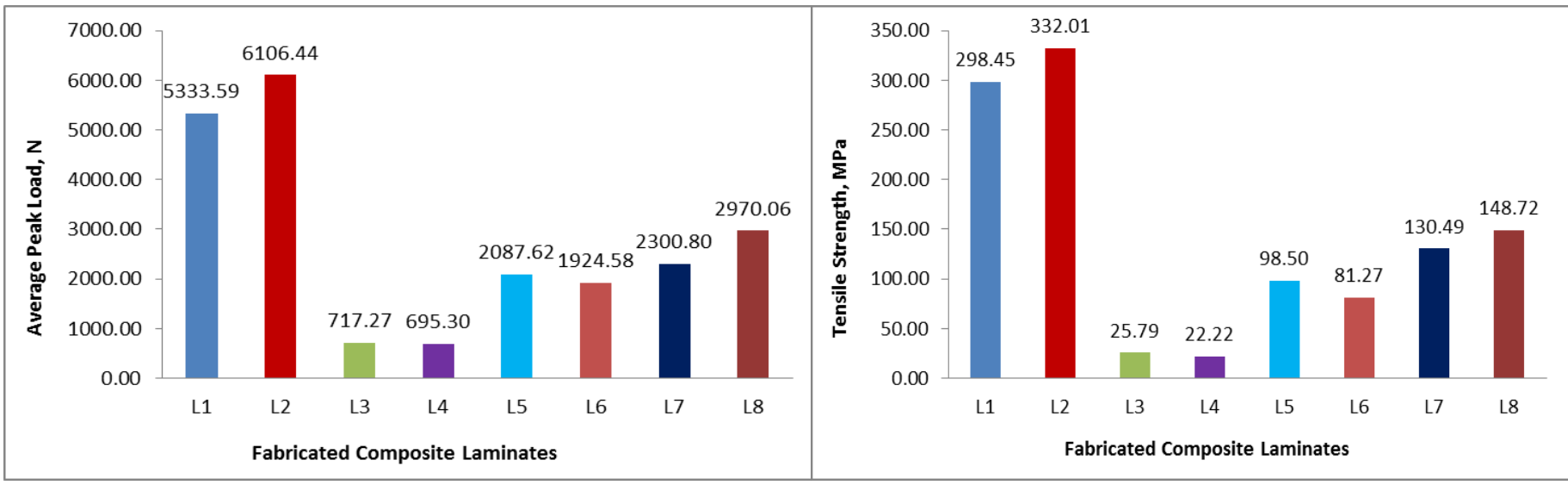

Chart: 1 Average Peak Load of different Laminates

\subsection{Flexural Test}

The flexural strength of fabricated composite laminates for different stacking sequences was estimated on the computerized universal testing

\section{Chart: 2Avg. Tensile Strength}

machine. For each laminate, six tests were conducted and a load /displacement plot was plotted based on the results generated during the test.

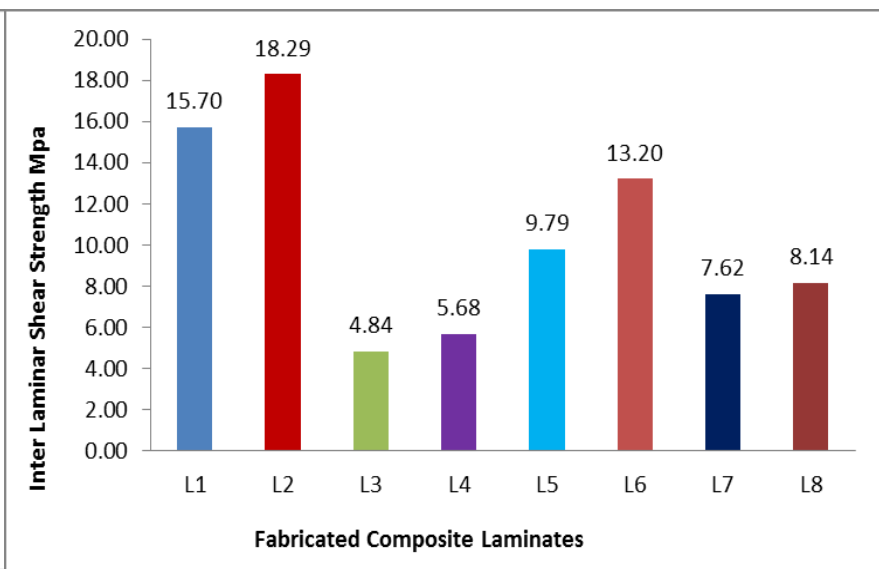


www.rspsciencehub.com

\subsection{Inter-Laminar Shear Strength}

The inter-laminar shear strength of fabricated composite laminates for different stacking sequences was estimated on the computerized universal testing machine.

\subsection{Water Absorption Test}

Water absorption test is very important to

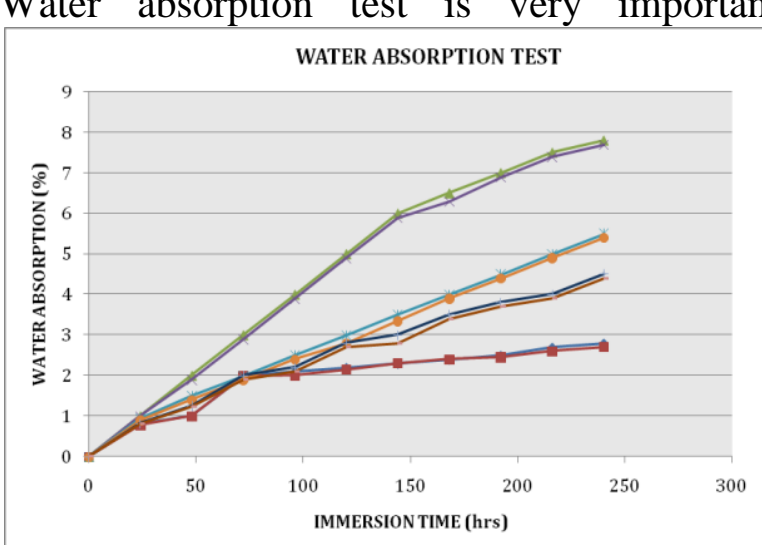

Volume 03 Issue 04S April 2021

determine the moisture absorptivity of the material. The percentage of weight gain in various composites with time duration is presented in Chart.

\subsection{Impact Strength}

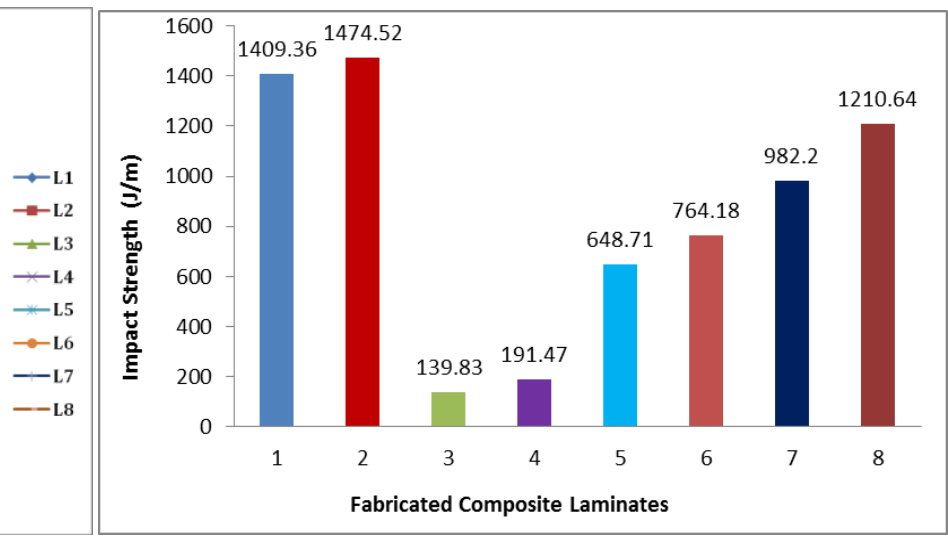

\section{Chart 5 Avg. Impact Strength Test}

\subsection{Scanning Electron Microscopy Analyses}

In the present study, the scanning electron microscope (SEM) images of fabricated composite laminates reinforced with Flax, Snake grass, and
Tealeaf were analyzed when they are subjected to a tensile test. Two-dimensional images are generated to identify their properties and crystalline structure.

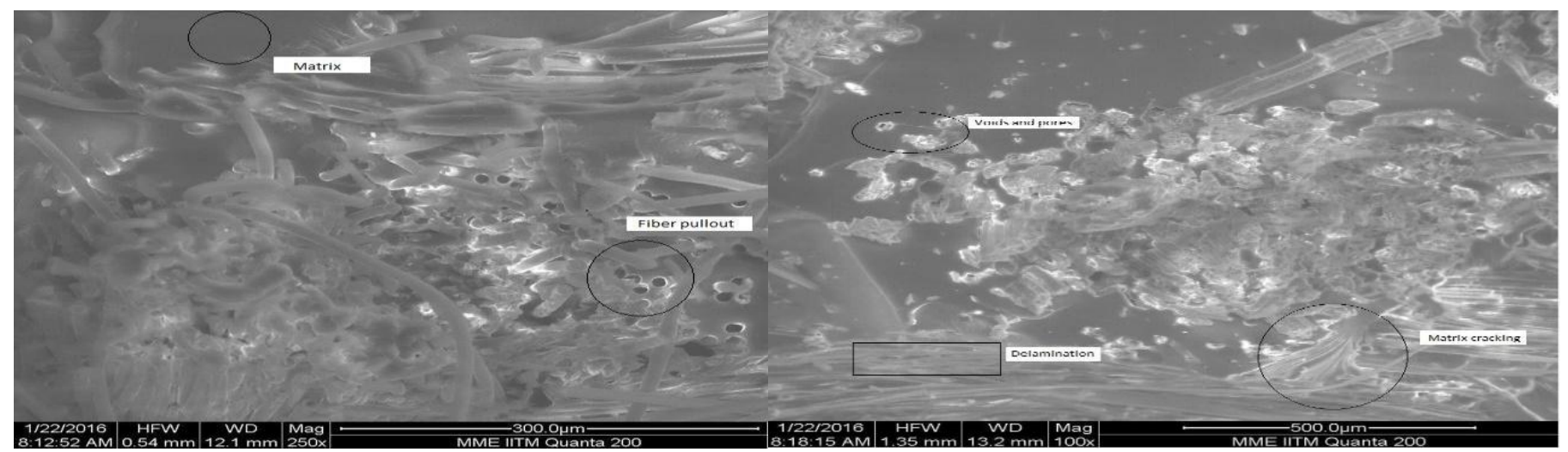

Fig.2 SEM Image of L1

Fig.3 SEM Image of $\mathrm{L} 2$

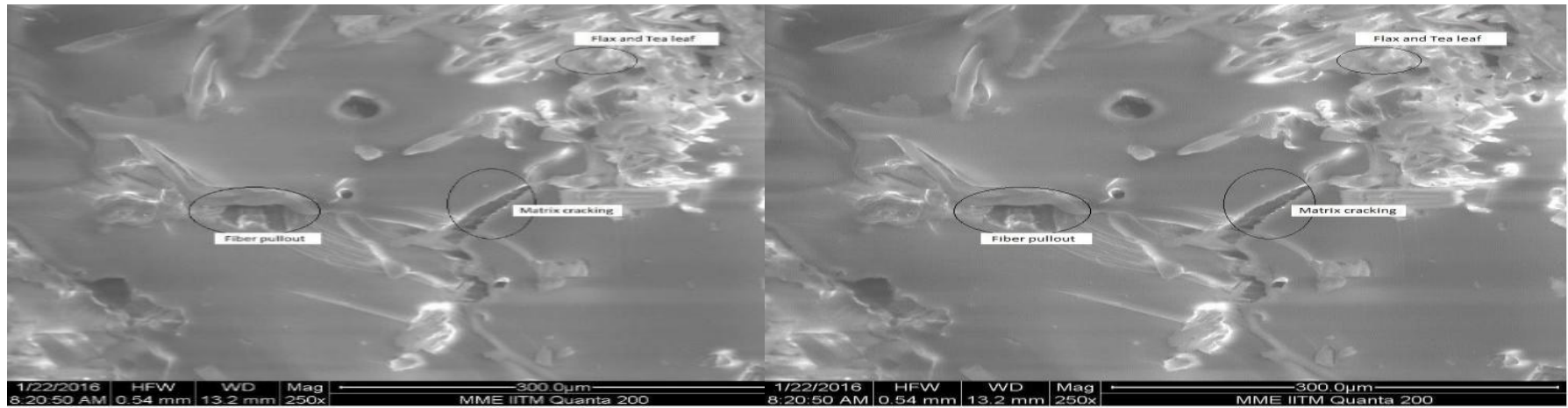

Fig.4 SEM Image of L3

Fig.5 SEM Image of L4 


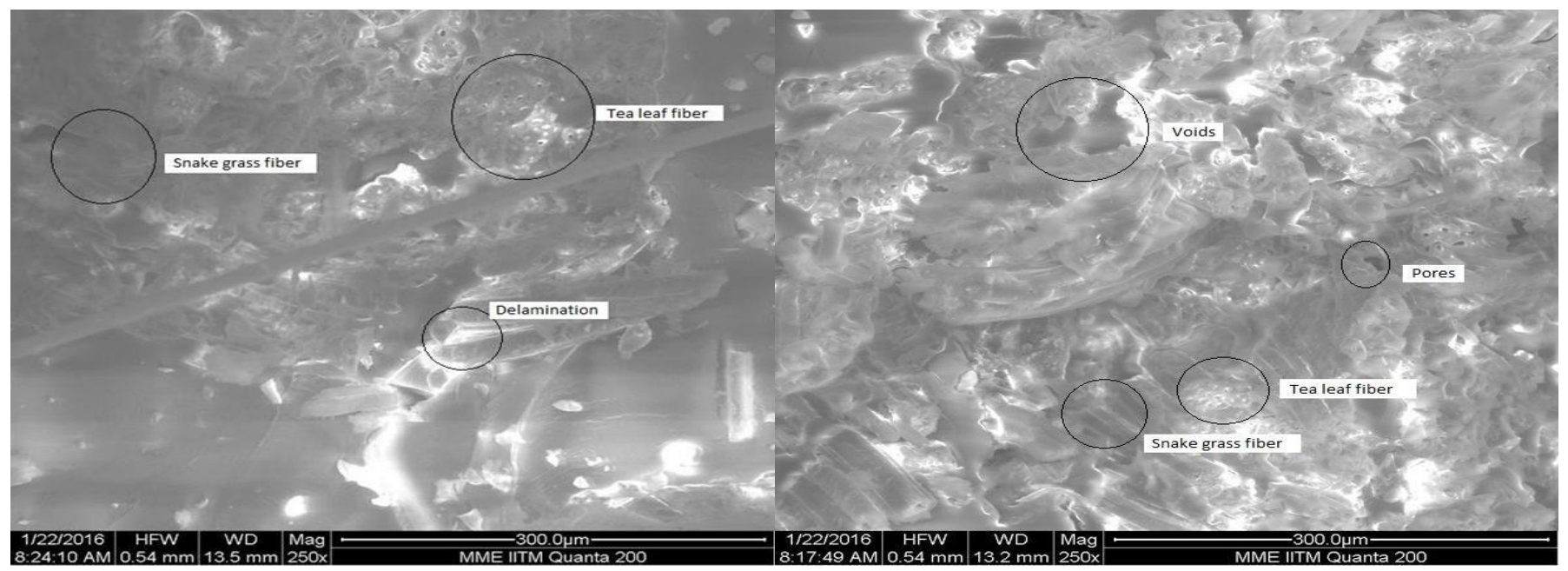

Fig.6 SEM Image of L5

Fig.7 SEM Image of L6

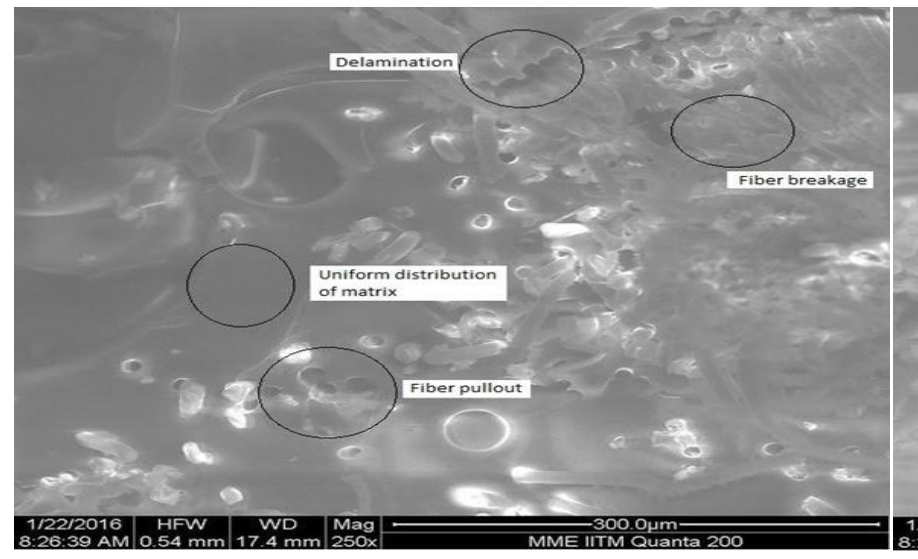

Fig.8 SEM Image of L7

\section{Discussion and Conclusion}

In the present research, hybrid composite laminates were successfully fabricated byusingcompressionmouldingtechniquewithdiffere ntwt. \%of fiber and matrix. Test specimens were prepared to evaluate different physical and mechanical properties as per the ASTM standard.

\section{a. Density}

The theoretical and experimental densities, the corresponding void fraction of the composite laminates were calculated and observed that the maximum void present in the composite laminates is only $1.753 \%$ which indicates that there is a better bonding between the matrix and the fiber at the interface regions. It is clear from the results that composite laminates fabricated with Snake grass and Tea leaf fibers contain more voids than the composite laminates fabricated with glass fiber. It is also observed that the composite laminates fabricated with different weight fractions of Flax, Snake grass, and Tealeaf hybrid composites exhibit better results compared to composites fabricated with the natural (Snake grass and Tealeaf) fibers.

\section{b. Tensile Strength}

The tensile strength of composite laminates was estimated as per ASTM standard to know the tensile characteristics. It is observed from the results that Flax and Snake grass with epoxy (L2) composite laminate exhibits better tensile strength as compared to other composite laminates. Enhancement in the tensile strength is due to better bonding, adhesion, and uniform dispersion of the fiber in the matrix. Composite laminates fabricated with Tea leaf L3 and L4 exhibit lower tensile strength due to the presence of pores at the interface between the fiber and the matrix and the weak interfacial adhesion. Further, L5 and L6 
hybrid composite laminates exhibit better tensile strength as compared to L3 and L4 because the addition of Flax fibers in combination with Snake grass and Tea leaf fiber enhances bonding and adhesion at the interfaces. L7 and L8 hybrid composites laminates exhibit better tensile properties compared to L3, L4, L5, and L6 laminates because of further addition of Flax fiber.

\section{c. Flexural Strength}

It is noticed that composite laminate L2 exhibits improved flexural strength as compared to other composite laminates. This is due to the better bonding and improved adhesion between fiber and matrix interface. L3 and L4 laminates fabricated with Tea leaf exhibit lower flexural strength. Further, the addition of Flax fiber along with the Snake grass and Tea leaf leads to enhanced flexural strength due to the favorable entanglement of the polymer chain. Hybrid composites laminates L7 and L8 induce more weight fractions of Flax compared to L5 and L6 but Flax fibers are stronger in tension compared to bending. This is the reason for minimum flexural strength in L7 and L8 composite laminates. Hence Flax, Snake grass, and Tealeaf fibers reinforced hybrid composites can be extensively used in the application where the bending load is important.

\section{d. Inter-Laminar Shear Strength}

It is noticed that composite laminate L2 exhibits better inter laminar shear strength as compared to other composite laminates. This is due to the better bonding and improved adhesion between fiber and matrix interface. L3 and L4 laminates exhibit a lower inter-laminar shear strength compared to other laminates because of poor dispersion of matrix which leads to the presence of voids in composite laminates (L3 and L4) fabricated with natural (Tealeaf) fibers. Further, enhanced ILLS in L5 and L6 compared to L7 and L8 is due to the presence of pores in the natural fibers leads to maximum utilization of matrix during fabrication, which enhances the bonding strength, in turn, minimizes the delamination of the fibermatrix interface.

\section{e. Impact Strength}

Enhancement in the impact strength in composite laminate L2 is due to better bonding, adhesion, and uniform dispersion of the fiber in the matrix. Laminates L3 and L4 exhibit low impact strength due to the presence of more voids. It is also observed from the results that L5, L6, L7, and L8 show the constant improvement in impact strength because of the hybridization of Flax Snake grass and Tea leaf fibers.

\section{f. Water Absorption Behaviors}

Composite laminates L1 and L2 show minimum water absorption characteristics due to the presence of Flax fiber. It is evident from the experiment that the composite laminates fabricated with Flax fiber in the outer layer lead to minimizing moisture absorption characteristics.

\section{g. Scanning Electron Microscopy Analyses}

In the present study, the scanning electron microscope (SEM) images of fabricated composite laminates reinforced with Flax, Snake grass, and Tealeaf were analyzed when they are subjected to a tensile test. Two-dimensional images are generated to identify their properties and crystalline structure. From the SEM images of fabricated composite laminates, it is observed that fiber pull-out, fiber breakage are realized in the composite laminates reinforced with Flax fibers due to better bonding between fiber-matrix interfaces. It is observed from the SEM images of Tea leaf fiber-reinforced composites that, presence of delamination of the fiber-matrix interface, cracks and voids, poor fiber-matrix adhesion, matrix cracking, and fiber pull-out. It is evident from the SEM images of hybrid composite laminates, which are exhibit better interfacial bonding between fiber-matrix interfaces, failure of the laminates due to the breakage of fibers rather than by the delamination. It is also noticed that Snake grass fibers are pulled out and Tea leaf fibers are broken because Tea leaf fibers alone absorb maximum load in the vertical direction compared to horizontal direction as it was in a plain-woven form which affects the mechanical properties of the laminates.

\section{Acknowledgment}

I wish to express our gratefulness to our Project guide Ms.S.Meinathan ME, Assistant Professor, Department of Mechanical Engineering for his invaluable guidance and constructive suggestion. I would like to express my profound thanks to my project coordinator and guide Mr.K.KANNAKUMAR ME, Assistant Professor 
in the Department of Mechanical Engineering thoughtful words helped me in completing my project successfully

\section{References}

[1] Akhila Padanattil, Jaanarayanan Karingamanna, MiniKM, 2017, Novel Hybrid Composites Based on Glass and Sisal Fiber for Retrofitting of Reinforced Concrete Structure, Journal on Construction and Building Materials133: (2017)146-153.

[2] Ayush Rathore and Pradhan M K, 2017 , Hybrid Cellulose Bio nanocomposites from banana andjute Fibers: A Review of Preparation , Properties and Applications ,Materials Today: Proceedings 4 (2017)39423951.

[3] Awal,Ansari, MNM, GracePua, Mohammad Jawaid, SaifulIslam, M2010,'A review on natural fiber reinforced polymer composite and its applications', International Journal of Polymer Science, http://dx.doi.org/10.1155/2015/243947.

[4] Amir N, Kamal AriffZainalAbidin, Faizzaty BintiMd Shiri, 2017, Effects of Fiber Configuration on Mechanical Properties of Banana Fiber/PP/MAPP Natural Fiber Reinforced Polymer Composite, Advancein Material\& Processing Technologies Conference:ProcediaEngineering184(2017)57 3-580.

[5] AnuarandZuraida,2011, 'ChemicalModificatio nofhemp,sisal,juteandkapokfibersbyalkalizatio n', Applied Polymer Science, vol. 84, pp.222234.

[6] Athijavamani,YM\&Martin,PA2009, 'Chemical modificationofhemp,sisal,juteandkapok fibers by alkalization', Journal of Applied Polymer Science, vol. 84, no. 12, pp.2222-2234.

[7] Abdelmouleh, M, Shyam, P, Piazza, M, Ren, H \& Wu, J 2007, 'Non Wood forestproducts 18 world bamboo resources', A thematic study prepared in the framework of the global forest resources assessment, Rome: Food and agriculture organization of the United Nations. 